\title{
A range correction for ICESat and its potential impact on ice-sheet mass balance studies
}

\author{
A. A. Borsa ${ }^{1}$, G. Moholdt ${ }^{1}$, H. A. Fricker ${ }^{1}$, and K. M. Brunt ${ }^{2,3}$ \\ ${ }^{1}$ Scripps Institution of Oceanography, San Diego, California, USA \\ ${ }^{2}$ Morgan State University, Baltimore, Maryland, USA \\ ${ }^{3}$ GESTAR, NASA Goddard Space Flight Center, Greenbelt, Maryland, USA
}

Correspondence to: A. A. Borsa (aborsa@ucsd.edu)

Received: 25 July 2013 - Published in The Cryosphere Discuss.: 30 August 2013

Revised: 16 January 2014 - Accepted: 16 January 2014 - Published: 3 March 2014

\begin{abstract}
We report on a previously undocumented range error in NASA's Ice, Cloud and land Elevation Satellite (ICESat) that degrades elevation precision and introduces a small but significant elevation trend over the ICESat mission period. This range error (the Gaussian-Centroid or "G-C" offset) varies on a shot-to-shot basis and exhibits increasing scatter when laser transmit energies fall below $20 \mathrm{~mJ}$. Although the G-C offset is uncorrelated over periods $\leq 1$ day, it evolves over the life of each of ICESat's three lasers in a series of ramps and jumps that give rise to spurious elevation trends of -0.92 to $-1.90 \mathrm{~cm} \mathrm{yr}^{-1}$, depending on the time period considered. Using ICESat data over the Ross and Filchner-Ronne ice shelves we show that (1) the G-C offset introduces significant biases in ice-shelf mass balance estimates, and (2) the mass balance bias can vary between regions because of different temporal samplings of ICESat. We can reproduce the effect of the G-C offset over these two ice shelves by fitting trends to sample-weighted mean G-C offsets for each campaign, suggesting that it may not be necessary to fully repeat earlier ICESat studies to determine the impact of the G-C offset on ice-sheet mass balance estimates.
\end{abstract}

\section{Introduction}

NASA's Ice, Cloud, and land Elevation Satellite (ICESat) (Schutz et al., 2005) was an Earth-orbiting laser altimeter mission that operated from 2003-2009. ICESat's primary task was to repeatedly measure surface elevations along fixed ground tracks over Earth's polar regions to help quantify the contribution of the ice sheets to contemporary sea level change. Many studies have used ICESat elevation data to estimate volume/mass changes of glaciers (Gardner et al., 2013), ice shelves (Pritchard et al., 2012), and ice sheets (Shepherd et al., 2012), and ICESat data have been combined with other measurements to increase the spatiotemporal coverage and resolution of surface change estimates. These complementary data include airborne laser altimetry from NASA's Operation IceBridge mission (Koenig et al., 2010; Kwok et al., 2012; Schenk and Csathó, 2012), gravity from the NASA/DLR GRACE mission (Riva et al., 2009), and elevations from ESA's ERS-1, ERS-2 and Envisat radar altimeters (Zwally et al., 2011; Hurkmans et al., 2012). ICESat will provide benchmark elevations for the planned ICESat-2 mission (Abdalati et al., 2010), which is planned for launch in 2017 and will extend the satellite laser altimeter record to $17 \mathrm{yr}$ or more.

Since the ice sheets are so vast, a $1 \mathrm{~cm}$ ice-equivalent elevation change over all grounded ice corresponds to a mass change of $134 \mathrm{Gt}$ and a sea level equivalent of $0.37 \mathrm{~mm}$. Centimeter-level systematic errors in satellite altimeter measurements are therefore crucial to ice mass balance estimates, and ICESat underwent rigorous calibration and validation to ensure that it would meet its accuracy target of $1.5 \mathrm{~cm} \mathrm{yr}^{-1}$ elevation change averaged over $100 \times 100 \mathrm{~km}$ regions (Zwally et al., 2002). ICESat's post-launch calibration of various geolocation parameters was based primarily on the minimization of elevation residuals from regularly repeated pointing maneuvers over the open ocean (e.g., Luthcke et al., 2005), with additional efforts to calibrate timing and geolocation using ground truth (Magruder et al., $2007,2010)$ and to mitigate the impact of detector saturation 
(Fricker et al., 2005). ICESat post-launch elevation validation included crossover analysis to determine ICESat's initial precision and accuracy (Shuman et al., 2006; Brenner et al., 2007), followed by long-term elevation comparisons with respect to stable and/or independently characterized reference surfaces (Fricker et al., 2005, Urban and Schutz, 2005; Borsa et al., 2007, 2008; Shuman et al., 2009).

Although ICESat was originally intended to be operated continuously throughout its mission (Abshire et al., 2003), concerns about laser reliability after the failure of the first ICESat laser led to it being operated campaign-style, whereby data were acquired in a series of $\sim 33$-day campaigns spaced 4-6 months apart (Table 1). The ICESat validation effort focused largely on documenting changes in ICESat elevation accuracy from campaign to campaign and between different releases of ICESat data (e.g., Fricker et al., 2005). Despite ongoing refinements in elevation retrieval (reflected in higher product release numbers), multiple studies have documented persistent instrument-related elevation biases between campaigns (Gunter et al., 2009; Riva et al., 2009; Siegfried et al., 2011). More importantly, these "intercampaign biases" exhibit statistically significant (albeit different) trends over the ICESat mission period (Urban et al., 2012). Furthermore, in the absence of a definitive set of intercampaign biases, researchers estimating ice volume/mass balance using ICESat data have taken different approaches with respect to intercampaign bias correction, with some making no correction (Pritchard et al., 2009; Gardner et al., 2013) and others applying biases from one of several sources (e.g., Gunter et al., 2009; Riva et al., 2009; Zwally et al., 2011; Shepherd et al., 2012).

This paper describes a previously unrecognized component of the ICESat intercampaign biases, an inadvertent range error (called the Gaussian-Centroid or "G-C" offset) that was introduced during the processing of Level 1 data. Correcting for this error improves the precision of individual elevation measurements and removes a small but significant anomalous elevation trend from ICESat data. Using global statistics for the GC offset and case studies over the salar de Uyuni in Bolivia and two Antarctic ice shelves, we demonstrate the potential impact that the correction has on ICESat elevation accuracy and ice sheet mass balance estimates.

\section{Data and analysis}

\subsection{ICESat campaigns}

Data collection during the ICESat mission took place during 18 separate campaigns between February 2003 and October 2009 (Table 1). In this paper, we refer to these campaigns using the standard convention of pairing the number of the operational laser with a letter designating each consecutive campaign for that laser (e.g., L2a is the first campaign for Laser 2, L3b is the second campaign for Laser 3, etc.).
Laser 1 operated for only 56 days before it failed and was flown only in ICESat's 8-day exact-repeat calibration orbit. Most published studies use data from L2a onwards (after the spacecraft had transitioned to its 91-day repeat orbit) so we will focus primarily on Lasers 2 and 3 . To clarify the time sequence of the laser campaigns, we note that Laser 2 was switched off after L2c and then back on again after Laser 3 failed, which is why campaigns L2d-L2f took place after L3k (the final Laser 3 campaign).

\subsection{ICESat data products}

ICESat data are publically available from the National Snow and Ice Data Center (NSIDC, http://nsidc.org/data/icesat/ index.html). Most users of ICESat elevation data choose one of several Level 2 data products containing the geolocated positions of individual laser footprints: GLA06 (Global Elevation Data), GLA12 (Antarctic and Greenland Ice Sheet Altimetry data), GLA13 (Sea Ice Altimetry Data), GLA14 (Global Land Surface Altimetry Data), and GLA15 (Ocean Surface Altimetry Data). Different assumptions about surface characteristics and the needs of investigators resulted in differentiation between these data products. Relevant to this study, elevations for GLA06, GLA12, GLA13 and GLA15 were calculated assuming laser reflection from smooth surfaces such as oceans and ice sheets, which generate simple return waveforms that can be represented accurately by a single Gaussian peak. Elevations for GLA14 were calculated assuming complex return waveforms that are best summarized by the centroid of the entire waveform, a distinction that will be discussed later.

In our work, we also used the Level 1A GLA01 (Global Altimetry Data) product to access the individual transmit and return waveforms for each laser shot; the Level 1B GLA05 (Global Waveform-based Range Correction Data) product for waveform parameters such as centroid, Gaussian fit, and skewness; and the Level 1B GLA06 product for instrument pointing, laser energy, surface reflectance, and various corrections. Although most users need only Level 2 data (processed geophysical variables) in their work, access to data in Level 1B (processed instrument) and Level 1A (raw instrument) products allows investigators such as ourselves to contribute to ICESat calibration and validation efforts.

\subsection{Elevation validation at the salar de Uyuni}

This study arose from a longstanding ICESat validation effort using a 45 -by- $54 \mathrm{~km}$ reference surface on the salar de Uyuni in Bolivia that we first surveyed with kinematic GPS in 2002 (Fig. 1) (Fricker et al., 2005; Borsa et al., 2007). Our digital elevation model (DEM) of the salar surface showed total topographic relief of only $80 \mathrm{~cm}$ over $50 \mathrm{~km}$, making the salar de Uyuni one of the flattest large natural surfaces on Earth. ICESat Track 360 (ascending) and Track 85 (descending) cross the Uyuni DEM, and over 300 individual 
Table 1. ICESat campaign metadata and G-C offset statistics. Campaigns are listed sequentially in time and are named as described in the text. Laser 2 campaigns are shown in grey to highlight the switching that occurs between lasers during the mission. The valid returns column gives the percentage of shots for which a surface elevation was recorded, which tends to drop as laser energy decreases.

\begin{tabular}{lcccccrr}
\hline Campaign & Start date & End date & \# Days & $\begin{array}{c}\% \text { Valid } \\
\text { returns }\end{array}$ & $\begin{array}{r}\text { \# Valid } \\
\text { returns }\end{array}$ & $\begin{array}{r}\text { G-C mean } \\
(\mathrm{cm})\end{array}$ & $\begin{array}{r}\text { G-C } \sigma \\
(\mathrm{cm})\end{array}$ \\
\hline L1a/L1b & $2 / 20 / 03$ & $3 / 29 / 03$ & 37 & $73 \%$ & 85862366 & 1.77 & 1.99 \\
L2a & $10 / 13 / 03$ & $11 / 19 / 03$ & 37 & $63 \%$ & 80770785 & 5.90 & 1.83 \\
L2b & $2 / 17 / 04$ & $3 / 21 / 04$ & 33 & $64 \%$ & 72697059 & 0.60 & 2.07 \\
L2c & $5 / 18 / 04$ & $6 / 21 / 04$ & 34 & $53 \%$ & 62361334 & -0.16 & 3.70 \\
L3a & $10 / 3 / 04$ & $11 / 8 / 04$ & 36 & $64 \%$ & 79437302 & -0.58 & 1.93 \\
L3b & $2 / 17 / 05$ & $3 / 24 / 05$ & 35 & $67 \%$ & 79778747 & -1.37 & 1.95 \\
L3c & $5 / 20 / 05$ & $6 / 23 / 05$ & 34 & $65 \%$ & 75890428 & -3.44 & 2.46 \\
L3d & $10 / 21 / 05$ & $11 / 24 / 05$ & 34 & $63 \%$ & 71662990 & -4.06 & 2.56 \\
L3e & $2 / 22 / 06$ & $3 / 28 / 06$ & 34 & $65 \%$ & 74789938 & -4.13 & 2.10 \\
L3f & $5 / 24 / 06$ & $6 / 26 / 06$ & 33 & $62 \%$ & 71172594 & -3.72 & 2.27 \\
L3g & $10 / 25 / 06$ & $11 / 27 / 06$ & 33 & $61 \%$ & 70179600 & -4.07 & 2.45 \\
L3h & $3 / 12 / 07$ & $4 / 14 / 07$ & 33 & $63 \%$ & 73058093 & -3.93 & 2.23 \\
L3i & $10 / 2 / 07$ & $11 / 5 / 07$ & 34 & $59 \%$ & 68161111 & -3.86 & 2.38 \\
L3j & $2 / 17 / 08$ & $3 / 21 / 08$ & 33 & $63 \%$ & 71872084 & -3.91 & 2.57 \\
L3k & $10 / 4 / 08$ & $10 / 19 / 08$ & 15 & $59 \%$ & 29447798 & -4.13 & 2.66 \\
L2d & $11 / 25 / 08$ & $12 / 17 / 08$ & 22 & $54 \%$ & 40865517 & -0.11 & 5.36 \\
L2e & $3 / 9 / 09$ & $4 / 11 / 09$ & 33 & $39 \%$ & 44606427 & 2.65 & 8.79 \\
L2f & $9 / 30 / 09$ & $10 / 11 / 09$ & 11 & $35 \%$ & 12844976 & 1.69 & 7.03 \\
Laser 1 avg & & & & $73 \%$ & & 1.77 & 1.99 \\
Laser 2 avg & & & & $51 \%$ & & 1.76 & 4.80 \\
Laser 3 avg & & & & $63 \%$ & & -3.38 & 2.32 \\
Average all & & & & $60 \%$ & & -1.38 & 3.13 \\
\hline
\end{tabular}

laser footprints from each track fall within the DEM boundaries. In 2009, we resurveyed the salar de Uyuni to check for topographic change that might impact ICESat elevation validation and found that the DEM - whose error we estimate to be less than $2.3 \mathrm{~cm}$ root mean square (Borsa et al., 2008) - had risen by an average of $2.5 \mathrm{~cm}$ (Brunt et al., 2009). Since we have no information about the nature of the surface change between 2002 and 2009 other than the small change in our DEMs, our best estimate of the actual surface at any intermediate epoch is a linear interpolation between the two DEMs. For the analysis used in this paper, we account for the effect of the surface change by linearly interpolating (nodeby-node) between the 2002 and 2009 DEMs to the date of each ICESat pass over the salar, creating a slightly different reference DEM for each track in each campaign.

At the salar de Uyuni, intercampaign biases for the latest release of the ICESat data (R633) ranged over $10 \mathrm{~cm}$, with elevation biases of up to $17 \mathrm{~cm}$ between repeated tracks within a single campaign (see Fricker et al., 2005 for a summary of our methods). These values are of similar magnitude to estimates by other investigators in different locations (Shuman et al., 2009; Siegfried et al., 2011; Urban et al., 2012). The salar de Uyuni is an ideal validation site - high-elevation (smaller tropospheric delay correction) with negligible cloud cover (little or no multiple scattering) and no topography (little or no elevation impact from pointing errors) - so we ex- pected higher accuracy in our elevation recovery than we observed. At the same time we realized that with such a large range of observed biases, we had an opportunity to use the salar de Uyuni to search for candidates for the unidentified error sources still affecting ICESat elevations.

\subsection{Correlations between transmit pulse parameters and ICESat elevations}

For this study, we undertook a systematic examination of the elevation impact of a number of ICESat instrument parameters, motivated by observations made by our group and other investigators that some of these parameters varied systematically from campaign to campaign (e.g., Fricker et al., 2005; Shuman et al., 2009). We hypothesized that at the salar de Uyuni we would be able to observe correlations between these parameters and the elevation biases still remaining after improvements in ICESat orbit determination, pointing and ranging over the mission lifetime (see http://nsidc.org/data/icesat/past_releases.html). Although we recorded and tracked instrument and environmental information as part of our validation activities, we had not previously looked for quantitative correlations between these parameters and the ICESat elevation biases over Uyuni.

Our analysis sought to explain variability in the elevation misfits (the differences between the ICESat and DEM 


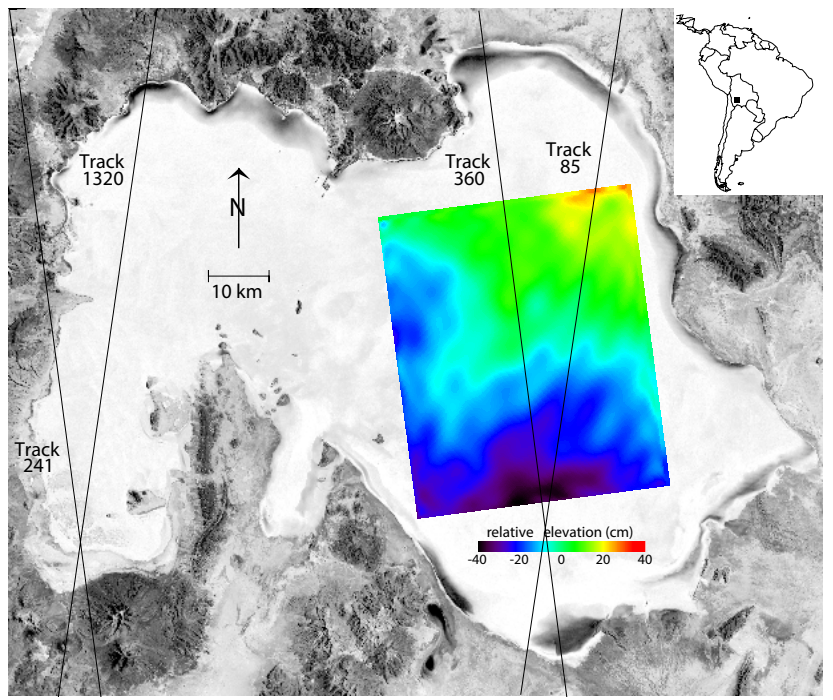

Fig. 1. The reference DEM used in this study, located on the salar de Uyuni in Bolivia. Topographic relief across the 45-by-54 km DEM is only $80 \mathrm{~cm}$, making this region of the salar one of the flattest natural surfaces on Earth. ICESat tracks 85 (descending) and 360 (ascending) cross the DEM and are used for range validation.

elevations) for all 8371 valid ICESat returns over the salar de Uyuni DEM, without regard to their chronological order. We regressed these misfits against a number of instrument/waveform parameters and found significant non-zero correlation between the misfits and (1) transmit pulse skewness, (2) transmit pulse eccentricity, (3) transmit gain, (4) transmit pulse energy, and (5) receive pulse energy. In the case of transmit pulse skewness, visual examination of the scatterplot between skewness and misfit (Fig. 2a) shows that the two are linearly correlated, with stronger correlations for individual campaigns than for the entire data set. Quantitatively, the linear Pearson correlation coefficient $R$ between skewness and misfit is 0.30 (and statistically significant) for the entire data set, with values for individual campaigns that reach 0.64 for L2b and L3c. Since parameters $1-2$ are related to the transmit pulse shape, and parameters $3-5$ are directly or indirectly related to transmit pulse amplitude, we concluded that characteristics of the transmit pulse were affecting ICESat range determination and were able to identify a potential mechanism for this effect in the ICESat Range Algorithm Theoretical Basis Document (ATBD) (Brenner et al., 2003).

ICESat's transmit and return pulses are recorded as histograms of energy versus time, with each histogram bin spanning $1 \mathrm{~ns}$ (equivalent to $15 \mathrm{~cm}$ in range). Following convention, we refer to these histograms as laser waveforms. ICESat Level 1 data post-processing identifies the times associated with reference points on the transmit and return waveforms and differences the two to obtain the pulse travel time, which is then scaled to obtain the range from ICESat to the surface.

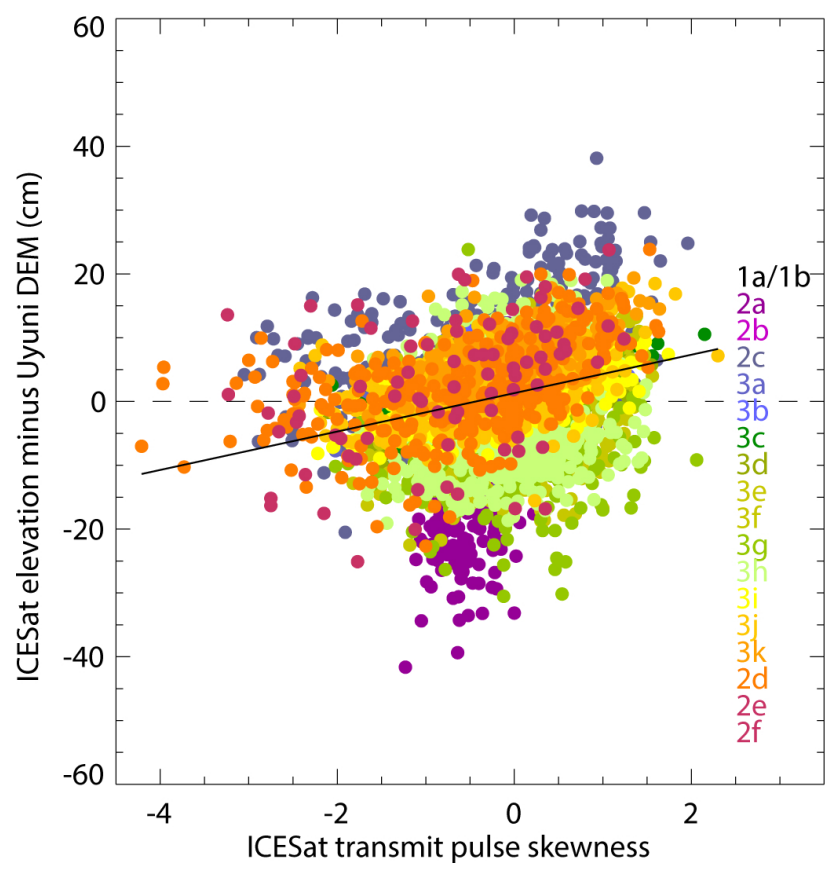

Fig. 2a. Scatterplot of ICESat elevation misfits versus the transmit pulse skewness for each shot, with the linear correlation between the two indicated by the black line. The Pearson correlation coefficient $R$ is 0.30 for the whole data set, with higher coefficients for most of the individual campaigns - up to 0.64 for L2b and L3c (see campaign color code at right of plot).

Two types of reference point are used in ICESat processing: the centroid of the waveform (yielding time $C_{\mathrm{T}}$ for the transmit waveform or time $C_{\mathrm{R}}$ for the return waveform) and the peak position of the Gaussian fit to the waveform (times $G_{\mathrm{T}}$ or $G_{\mathrm{R}}$ ). For consistency, travel times should be calculated using the same type of reference point on both the transmit and the return waveforms (e.g., $T=C_{\mathrm{R}}-C_{\mathrm{T}}$ or $T=G_{\mathrm{R}}-G_{\mathrm{T}}$ ). We noticed, however, that two different reference points were specified in a figure in the ICESat Range ATBD, with the range calculated from the Gaussian-Centroid time difference $G_{\mathrm{R}}-C_{\mathrm{T}}$ (see Fig. 3). This is problematic because any difference between the transmit centroid and transmit Gaussian peak location also appears in the return centroid and Gaussian. While this has no effect when pulse travel time is calculated between centroids or between Gaussians, when mixed reference points are used it results in a range error that propagates through the ICESat geolocation process to yield an elevation error of opposite sign.

\subsection{An ICESat range error: the Gaussian-Centroid (G-C) offset}

Although Gaussian-minus-centroid (or G-C) timing was not intended to be used for ICESat range determination, NASA's ICESat Science Computing Facility confirmed that G-C timing was implemented through data release R633 for all 


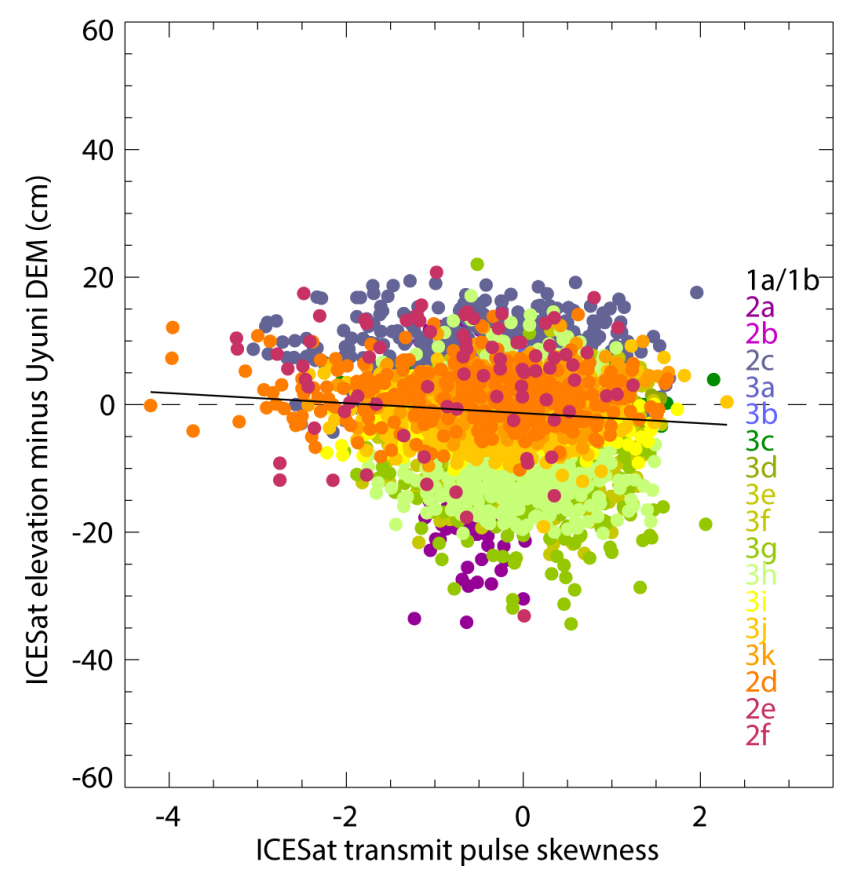

Fig. 2b. Same as Fig. 2a, but using G-C-corrected ICESat elevations. $R$ is now only -0.09 for the whole data set, indicating that the G-C correction has removed most of the spurious correlation between transmit pulse skewness and ICESat elevations.

ICESat products except GLA14 (land surface elevations). As discussed earlier, in the case of GLA14 the expectation was that over land the reflecting surface would be complex and the elevation of the laser footprint location would be best summarized by the centroid of the return waveform. GLA14 elevations were therefore implemented using centroid-tocentroid $\left(C_{\mathrm{R}}-C_{\mathrm{T}}\right)$ timing and are not impacted by the G-C offset. For GLA06, GLA12, GLA13, and GLA15, where return waveforms were expected to be primarily single-peaked and Gaussian-shaped, a Gaussian fit was used to determine the time of the return waveform and was (incorrectly) differenced with the centroid of the transmit waveform.

Fortunately, the range error in these four data products due to G-C timing (henceforth the "G-C offset") can be exactly reproduced using the transmit pulse parameters available in the ICESat GLA05 data product:

$$
\begin{aligned}
\mathrm{G}-\operatorname{Coffset}(\mathrm{m}) & =\left(\mathrm{GLA} 05 . \mathrm{d} \_\operatorname{parm} \operatorname{Tr}(2)\right. \\
& \left.-\operatorname{GLA05.d\_ locTr}\right) \cdot c / 2,
\end{aligned}
$$

where d_locTr is the time in ns corresponding to the transmit waveform centroid (parameter names are those used in the GLA05 data product), d_parm $\operatorname{Tr}(2)$ is the time in ns of the peak of the Gaussian fit to the transmit waveform, and $c$ is the speed of light defined as $0.30 \mathrm{~m} \mathrm{~ns}^{-1}$. The elevation impact of the G-C offset can be removed by adding the offset from (1) directly to ICESat elevations, a step we will refer to as the "G-C correction" hereafter. Alternatively, investigators

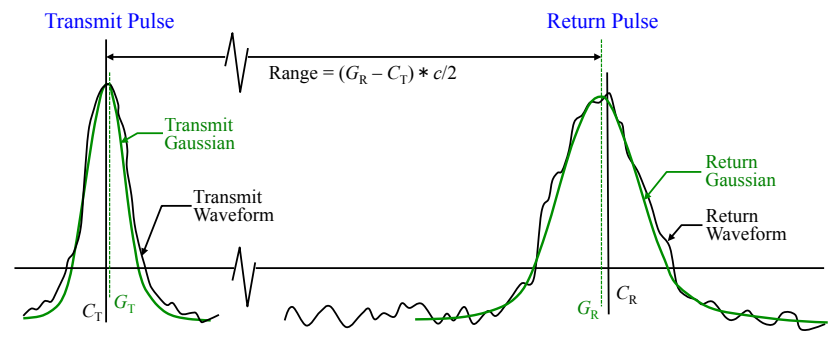

Fig. 3. ICESat range determination illustration, adapted from Brenner et al. (2003). The transmit and return waveforms are shown in black, and the Gaussian fits to those waveforms are shown in green. The centroids of the transmit $\left(C_{\mathrm{T}}\right)$ and return $\left(C_{\mathrm{R}}\right)$ waveforms are indicated by the solid black vertical lines, and the peak locations of the Gaussian fits to the transmit $\left(G_{\mathrm{T}}\right)$ and return $\left(G_{\mathrm{R}}\right)$ waveforms are indicated by the dotted green vertical lines. The ICESat range determination algorithm that was implemented through data release R633 used the time difference between the return Gaussian peak and the centroid of the transmit waveform (multiplied by the speed of light $c$ and divided by 2 to get one-way range), which introduces a range error equal to $\left(G_{\mathrm{T}}-C_{\mathrm{T}}\right)$.

can apply the G-C correction from files provided by the National Snow and Ice Data Center (http://nsidc.org/data/icesat/ correction-to-product-surface-elevations.html). Technically, the G-C offset/correction should also be scaled by the cosine of the laser pointing angle measured from nadir, but since this angle is rarely over $3^{\circ}$, the scaling is $<1 \mathrm{~mm}$ and is negligible in most cases.

After calculating and applying the G-C correction to ICESat returns from the salar de Uyuni, we revisited our analysis in Sect. 2.4 and confirmed that the G-C offset was responsible for most of the observed correlation between ICESat elevations and the listed waveform/instrument parameters. As Fig. 2b illustrates for transmit pulse skewness, we observed that correlations drop to nearly zero after the G-C correction is applied to ICESat elevations.

\subsection{G-C offset characteristics for ICESat's three lasers}

We took the entire ICESat data set and used Eq. (1) to calculate the G-C offset for all laser shots that resulted in a valid surface return. Ordering the pulses sequentially by laser shot, we found significant and systematic differences in the G-C offset over the life of each laser and between the three lasers (Fig. 4; Table 1).

During its short 56-day life, Laser 1 exhibited a mean G-C offset of $1.77 \mathrm{~cm}$, a G-C offset standard deviation of $1.99 \mathrm{~cm}$, and little change in G-C offset behavior over time (Fig. 4a). Laser 2 had almost the same mean offset as Laser $1(1.76 \mathrm{~cm})$, but more than double the $\mathrm{G}-\mathrm{C}$ offset standard deviation $(4.80 \mathrm{~cm}$; Fig. $4 \mathrm{~b})$. In fact, Laser 2 exhibited a four-fold increase in G-C offset standard deviation from L2c to L2f, which was associated with low (sub-20 mJ) and declining transmit energy. Increased variance is expected with 

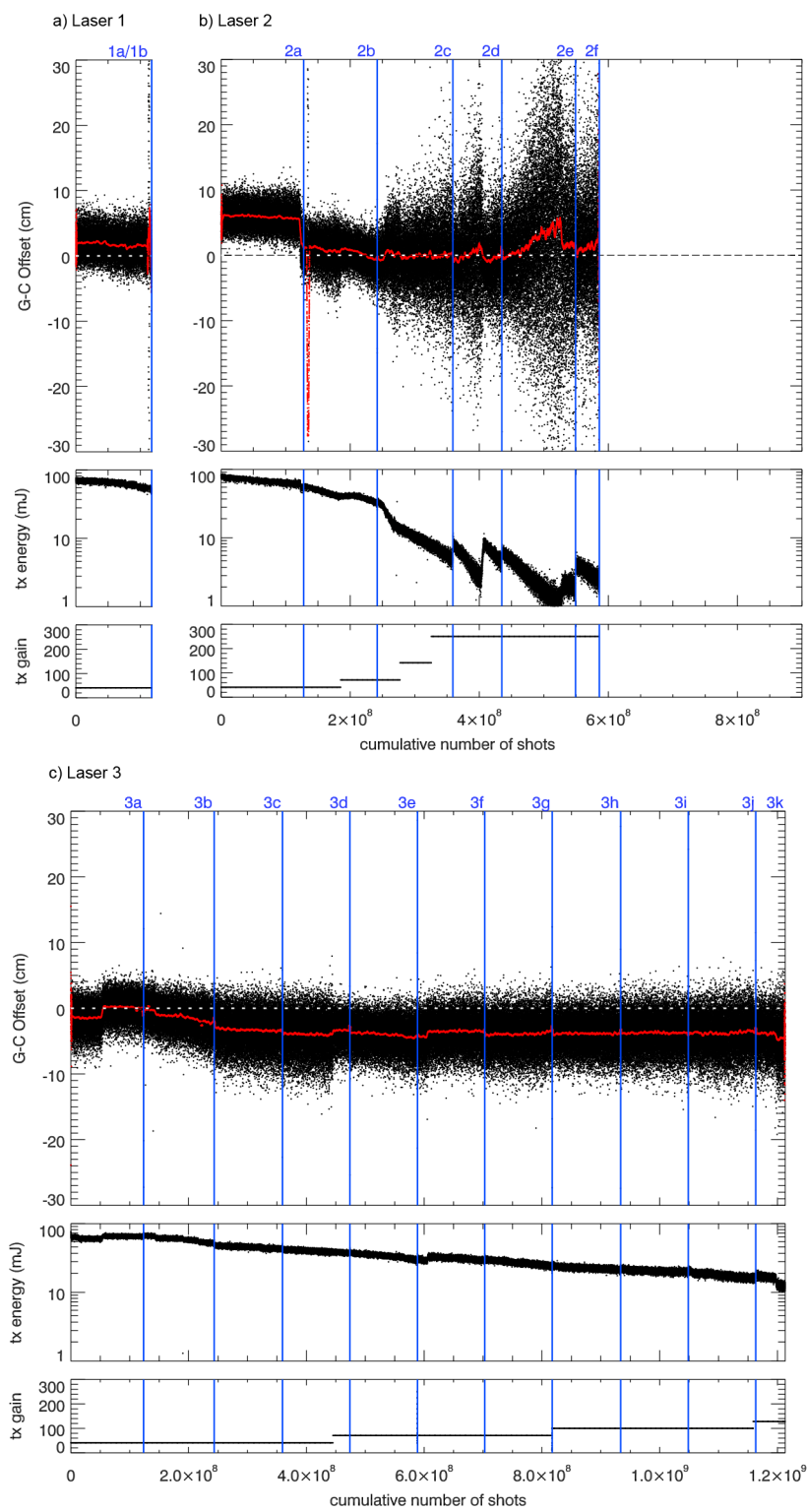

Fig. 4. The G-C offset, transmit energy, and transmit gain for Laser 1 (a), Laser 2 (b), and Laser 3 (c), ordered sequentially by the cumulative number of shots for each laser. The red line in the top plot is the 10000-shot moving average of the G-C offset. ICESat campaigns are named in blue at the top of the plots and are delineated by blue lines marking the end of each campaign period. The scatter in the G-C offset grows as transmit energy drops, especially below $20 \mathrm{~mJ}$.

low transmit energy because the accompanying decrease in the signal-to-noise ratio of the laser waveforms (once the transmit gain can no longer be increased to compensate) degrades the precision of centroid determination and Gaussian fitting (Fricker et al., 2005). In addition, there were significant changes in the moving average of the G-C offset (red line in Fig. 4), including (1) a $5 \mathrm{~cm}$ drop at the end of L2a that is associated with an instantaneous $10 \mathrm{~mJ}$ fall in transmit

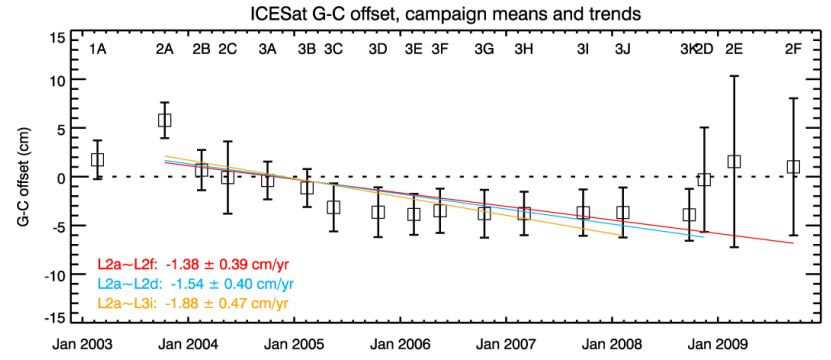

Fig. 5. G-C offset campaign means and trend estimates for selected data spans from Table 2, Trend A. The box symbols indicate the mean values of the G-C offset for each campaign, the error bars show the offset standard deviations, and the different lines are G$\mathrm{C}$ offset trends estimated for different data periods using inversevariance weighing. The G-C offset has a bigger impact on elevation trends when campaigns at the end of the mission are excluded.

power and is probably due to the failure of one of the diode pump bars, (2) a large negative spike at the beginning of L2b during the period ICESat was in sun acquisition mode, and (3) an inverse correlation with transmit power beginning in L2d, which was when transmit energy fell and remained below $10 \mathrm{~mJ}$.

By contrast, Laser 3 showed much more stable G-C offset behavior, due in part to its higher transmit energies (Fig. 4c). Overall, Laser 3 had a lower mean G-C offset value $(-3.38 \mathrm{~cm})$ than the other two lasers and a relatively constant standard deviation $(2.32 \mathrm{~cm})$ whose value was close to that of Laser 1 . The $\mathrm{G}-\mathrm{C}$ offset moving average started around $0 \mathrm{~cm}$, jumped $3 \mathrm{~cm}$ in the middle of L3a (when the laser temperature was increased from 13.8 to $16.0^{\circ} \mathrm{C}$ ), and then gradually dropped by $4 \mathrm{~cm}$ through $\mathrm{L} 3 \mathrm{~d}$ and remained consistent up to the end of L3k.

\section{Results and discussion}

\subsection{Trend in the G-C offset over the ICESat mission}

There are two direct effects of the G-C offset: (1) it increases the shot-to-shot variability of ICESat elevations (especially at low transmit energies) and (2) it shifts the mean elevation for most campaigns. Of greater relevance to ice-sheet mass balance studies is a secondary effect due to the fact that when ordered in time, the changes in the mean G-C offset between campaigns exhibit time-correlated behavior over the mission period (Fig. 5) that could potentially be interpreted as real surface elevation change. In particular, the high values of the G-C offset for all three campaigns at the end of the mission (L2d-L2f) generate erroneously low elevations that could be interpreted as suddenly higher ice sheet mass-loss rates at the end of the mission period.

Most published studies using ICESat data for ice sheet mass balance have derived surface change estimates by fitting linear trends in time through all elevations over a target 
Table 2. G-C offset trend estimates (and formal 1-sigma errors) using different data periods and different least-squares weighting applied to each campaign. Trend A uses inverse-variance weighting derived from the G-C offset statistics in Table 1, Trend B uses uniform weighting, and Trend $\mathrm{C}$ uses weights derived from global ICESat sampling by campaign. These trend estimates represent the impact of the G-C correction on $\mathrm{d} h / \mathrm{d} t$, indicating that all ICESat-derived ice elevation change estimates should become more negative once the G-C offset is removed.

\begin{tabular}{llcc|cc|cc}
\hline $\begin{array}{l}\text { Begin } \\
\text { campaign }\end{array}$ & $\begin{array}{l}\text { End } \\
\text { campaign }\end{array}$ & \multicolumn{2}{c|}{$\begin{array}{c}\text { G-C Trend A } \\
\left(\mathrm{cm} \mathrm{yr}^{-1}\right)\end{array}$} & \multicolumn{2}{|c|}{$\begin{array}{c}\text { G-C Trend B } \\
\left(\mathrm{cm} \mathrm{yr}^{-1}\right)\end{array}$} & \multicolumn{2}{|c}{$\begin{array}{c}\text { G-C Trend C } \\
\left(\mathrm{cm} \mathrm{yr}^{-1}\right)\end{array}$} \\
\hline L2a & L3i & -2.13 & \pm 0.53 & -1.90 & \pm 0.48 & -1.90 & \pm 0.51 \\
L2a & L3j & -1.88 & \pm 0.47 & -1.62 & \pm 0.41 & -1.76 & \pm 0.47 \\
L2a & L3k & -1.64 & \pm 0.41 & -1.39 & \pm 0.36 & -1.55 & \pm 0.42 \\
L2a & L2d & -1.54 & \pm 0.40 & -1.00 & \pm 0.32 & -1.17 & \pm 0.38 \\
L2a & L2e & -1.48 & \pm 0.40 & -0.62 & \pm 0.29 & -1.05 & \pm 0.37 \\
L2a & L2f & -1.38 & \pm 0.40 & -0.36 & \pm 0.26 & -0.92 & \pm 0.36 \\
\hline
\end{tabular}

area (Schenk and Csathó, 2012 offer an alternative methodology that accounts for non-linear features in elevation time series). Since we wanted to understand how the G-C offset might have impacted these mass balance estimates, we estimated the trend of the G-C offset trend over several time periods. First, we performed a linear regression against time of the global mean G-C offsets for campaigns L2a to L2f (the entire mission), with inverse-variance weights for each campaign calculated from the G-C offset standard deviations (all data are from Table 1). This choice of weighting lowers the contribution of high-variance data points, which in this case are the three Laser 2 campaigns at the end of the mission. For the L2a-L2f period, we obtained a trend of $-1.4 \pm 0.4 \mathrm{~cm} \mathrm{yr}^{-1}$, which is statistically different from zero at the 3-sigma level. Since many published studies do not include the later ICESat campaigns in their analysis, we also report trends for other data periods (Table 2, Trend A). As Table 2 and Fig. 5 show, the fewer campaigns used at the end of the ICESat mission, the more negative the trend of the G-C offset: up to $-2.1 \pm 0.5 \mathrm{~cm} \mathrm{yr}^{-1}$ in the case of data spanning only the period between L2a to L3i.

\subsection{Potential impact of the G-C offset on ICESat elevation trends}

The negative trend in the G-C offset contributes an erroneous positive trend in ICESat elevations that could be interpreted as real surface change. However, the trends we calculated in Sect. 3.1 are not our best estimate of the actual effect of the G-C offset on ICESat-derived elevation change because of differences in linear regression weighting, as we discuss below.

ICESat investigators typically estimate volume change by integrating many independent elevation trend estimates over a region of interest. If ICESat elevation data are not corrected for the G-C offset, the G-C offsets on all the individual laser shots will propagate through the linear regression used to estimate elevation trends and will introduce an error. Importantly, this trend error is highly dependent on the weighting applied to the elevations in the regression (see Appendix A). Since most investigators use constant weighting for all returns (e.g., Shepherd et al., 2012), we repeated the linear regressions from Sect. 3.1 using a uniform weight on each campaign of $1 / 4 \mathrm{~cm}^{-2}$ (corresponding to a $2.0 \mathrm{~cm}$ standard deviation). The result was less negative G-C offset trends (Table 2, Trend B), with the biggest change for the longest data periods (e.g., for L2a-L2e and L2a-L2f). Using a different value for the uniform weight will not change these trend estimates, although it will change the formal error.

In addition, the number of ICESat measurements in each campaign (i.e., spatio-temporal sampling) also affects how the G-C offset will affect elevation trend estimates. For example, campaign L2f had fewer returns than any other campaign because it was only 11 days long and because its low laser transmit energy resulted in a low percentage of valid returns being recorded due to attenuation by clouds. There are relatively few L2f elevations included in the many thousands of elevation trend estimates made over an ice sheet, which means that campaign L2f elevations (and therefore the G-C offset for L2f) are typically underweighted in the overall ice sheet elevation trend.

We estimated the impact of sampling on the G-C trend by modifying the uniform-variance regression weights above to include a term for the relative number of returns expected for each campaign (Appendix A). The resulting trend estimates (Table 2, Trend C) are more negative than they would be if sampling were ignored. This is due to the lower weighting of the L2d-L2f campaigns (whose low energies resulted in fewer returns than in earlier campaigns), which reduced the impact of their relatively high G-C offsets on the G-C trend estimate. These trends are our best approximation of the impact of removing the G-C offset from ICESat elevations, although differences in relative ICESat sampling from the global campaign averages (due to regional effects or data editing protocols) are likely to cause the impact of the G-C offset in specific cases to vary from our estimates. 


\subsection{Power spectrum of the G-C offset}

To determine if there is regional variation in the G-C offset, we examined the G-C offset power spectrum to look for temporal correlations that could map into spatial patterns. For this analysis we could not use G-C offsets calculated from the centroid and Gaussian parameters in the GLA05 data product, since shots without a valid return (see Table 1) did not undergo Gaussian fitting during ICESat data processing. Spectral estimation requires continuous time series, so we retrieved transmit waveform records from the GLA01 data product, estimated Gaussian fits for every ICESat transmit pulse, and recalculated the G-C offset using Eq. (1) and the original GLA05 centroids. The G-C offsets calculated this way deviate from the GLA05-derived offsets by $0.0 \pm 2.5 \mathrm{~mm}$ (1-sigma) overall and are continuous over each campaign.

We made G-C offset power spectral density (PSD) estimates for each of the 18 ICESat campaigns using a singlewindow Fast Fourier Transform (FFT) with a Hamming taper. In all cases, the power spectra are flat at frequencies higher than $10^{-5} \mathrm{~Hz}$, except for narrow spectral peaks at $0.000173 \mathrm{~Hz}$ (the orbital frequency of ICESat) and various multiples thereof (Fig. 6). If there were any jumps or ramps in the G-C offset time series during a campaign, these are manifested as a ramp in the spectrum at frequencies lower than $10^{-5} \mathrm{~Hz}$ (e.g., Fig. 6, left). What these results indicate is that the G-C offset generally behaves like white noise over periods shorter than a day (about 15 full orbits), with superimposed sinusoidal variability over distances $\leq 1$ orbit. Although this implies some degree of along-track correlation, because successive ICESat ground tracks fill in between earlier tracks, changes in the G-C offset are almost uniformly distributed over a broad area such as an ice sheet. The global characteristics of the G-C offset should thus be a good first approximation to how it manifests in any regional analysis.

\subsection{Impact of the G-C Offset on ICESat $\mathrm{d} h / \mathrm{d} t$ estimates over ice shelves}

In order to test our assumptions about the impact of the G-C offset on ICESat trend estimates, we did an analysis of data over the Ross and Filchner-Ronne ice shelves in Antarctica. These ice shelves are large, relatively featureless, and are a good analogue for the low-relief interiors of the ice sheets. For each ice shelf we estimated elevation trends for campaigns L2a-L2f using ICESat data with and without the G-C offset. For this analysis, we followed the standard approach of simultaneously estimating planar slopes $(\mathrm{d} h / \mathrm{d} x, \mathrm{~d} h / \mathrm{d} y)$ and temporal trends $(\mathrm{d} h / \mathrm{d} t)$ for nearby footprints along segments of ICESat repeat tracks using least-squares estimation with unit weighting (e.g., Smith et al., 2009; Gardner et al., 2013). We used saturation-corrected and tide-corrected elevations from the ICESat GLA12 data product, "retided" the elevations using a more accurate tide-model (Padman et al., 2002; Fricker and Padman, 2006), and estimated $\mathrm{d} h / \mathrm{d} t$ only for tracks that were repeated during four or more campaigns. Finally, for each ice shelf and data set, we calculated a latitude-weighted average $\mathrm{d} h / \mathrm{d} t$ value by applying an empirical function of the satellite orbit convergence towards the geographical poles (Gardner et al., 2013). This provides a weighted estimate of $\mathrm{d} h / \mathrm{d} t$ that is consistent with gridding methods, although without the need for spatial interpolation.

For both ice shelves, the impact of the G-C correction was that the average $\mathrm{d} h / \mathrm{d} t$ value became more negative, on the order of $0.6 \mathrm{~cm} \mathrm{yr}^{-1}$. For the Ross Ice Shelf, the average $\mathrm{d} h / \mathrm{d} t$ value changed by $-0.68 \mathrm{~cm} \mathrm{yr}^{-1}$ after applying the G-C correction (from $+0.16 \mathrm{~cm} \mathrm{yr}^{-1}$ to $-0.52 \mathrm{~cm} \mathrm{yr}^{-1}$ ). For the Filchner-Ronne Ice Shelf, the average $\mathrm{d} h / \mathrm{d} t$ value changed by $-0.49 \mathrm{~cm} \mathrm{yr}^{-1}$ after applying the G-C correction (from $+1.78 \mathrm{~cm} \mathrm{yr}^{-1}$ to $+1.29 \mathrm{~cm} \mathrm{yr}^{-1}$ ). The reason the impact of the G-C correction is different on each ice shelf is because the spatio-temporal sampling in each campaign is different. Most relevant is the undersampling of the FilchnerRonne Ice Shelf in campaign L2a relative to the Ross Ice Shelf (see Table 3), which slightly flattens the G-C correction trend. This can be understood by observing that reducing the weight of L2a in Fig. 5 will mitigate the impact of its high G-C offset and thus flatten the slope of the linear fit to the G-C offsets. Sampling in campaigns L3g and L3i is also different on the two ice shelves, but these differences matter less because L3g and L3i are close to the center of the time series and because their mean G-C offset values are similar to those of nearby campaigns.

The G-C correction significantly changed the mass balance of the two ice shelves we examined. Because of hydrostatic equilibrium, a given change in surface elevation equates to about nine times more change in ice thickness, greatly magnifying the mass balance impact of systematic measurement errors. In the case of the Ross Ice Shelf, the $-0.68 \mathrm{~cm} \mathrm{yr}^{-1}$ change in average $\mathrm{d} h / \mathrm{d} t$ from the G-C correction implied a mass balance correction of $-29 \mathrm{Gt} \mathrm{yr}^{-1}$ af ter accounting for hydrostatic equilibrium. The mass balance correction for the Filchner-Ronne Ice Shelf was $18 \mathrm{Gt} \mathrm{yr}^{-1}$.

For comparison, we also approximated the impact of the $\mathrm{G}-\mathrm{C}$ correction on the ice shelf elevation trend using linear fits to the mean G-C offsets of each campaign. For each ice shelf, we linearly regressed the mean G-C offsets from Table 1 against time, using the campaign sampling from Table 3 to derive appropriate weights via Eq. (A10) (Appendix A). Our estimates for the impact of the G-C correction using this method were $-0.61 \mathrm{~cm} \mathrm{yr}^{-1}$ for the Ross Ice Shelf and $-0.49 \mathrm{~cm} \mathrm{yr}^{-1}$ for the Filchner-Ronne Ice Shelf, which are both within $1 \mathrm{~mm} \mathrm{yr}^{-1}$ of the actual $\mathrm{d} h / \mathrm{d} t$ values calculated by applying the G-C correction and reprocessing the data set. This suggests that it may not be necessary to fully repeat earlier ICESat studies to determine the impact of the G-C correction as long as the local sampling and explicit weighting scheme for each campaign is known. 
Table 3. ICESat sampling of the Ross and Filchner-Ronne ice shelves for the elevation trend estimates in Sect. 3.4. We list the number of shots used by campaign over the entire ice sheet $\left(S_{i}\right.$ in Eq. A10), as well as the relative campaign sampling weights (expressed as a percentage of the maximum number of shots on that ice shelf for any campaign). There are large differences in relative campaign sampling between the two ice shelves for L2a, L3g and $\mathrm{L} 3 \mathrm{j}$, which results in different estimates for the elevation trend impact of the G-C offset.

\begin{tabular}{lcc|cc}
\hline \multirow{2}{*}{ Campaign } & \multicolumn{2}{c|}{ Ross } & \multicolumn{2}{c}{ Filchner-Ronne } \\
& \# Shots used & \% Max & \# Shots used & \% Max \\
\hline L2a & 395218 & 96 & 179955 & 68 \\
L2b & 285648 & 69 & 198316 & 75 \\
L2c & 378640 & 92 & 244073 & 92 \\
L3a & 377854 & 91 & 245864 & 93 \\
L3b & 335248 & 81 & 202618 & 77 \\
L3c & 363814 & 88 & 264081 & 100 \\
L3d & 358902 & 87 & 197763 & 75 \\
L3e & 291486 & 71 & 151919 & 58 \\
L3f & 368413 & 89 & 234540 & 89 \\
L3g & 413425 & 100 & 169199 & 64 \\
L3h & 329989 & 80 & 227046 & 86 \\
L3i & 384517 & 93 & 235922 & 89 \\
L3j & 262832 & 64 & 220324 & 83 \\
L3k & 160299 & 39 & 127620 & 48 \\
L2d & 189205 & 46 & 123881 & 47 \\
L2e & 261577 & 63 & 190585 & 72 \\
L2f & 104189 & 25 & 49165 & 19 \\
\hline
\end{tabular}

\subsection{Impact of the G-C offset on ICESat intercampaign biases}

There have been many independent estimates made of ICESat intercampaign biases (e.g., Siegfried et al., 2011; Zwally et al., 2011; Shepherd et al., 2012; Ewert et al., 2012; Gunter et al., 2013; Hofton et al., 2013), many of which were directly compared in Urban et al. (2012). There is little consensus between estimates of individual biases or bias trends: the seven estimates considered in Urban et al. (2012) yielded biases that differed by up to $20 \mathrm{~cm}$ for any single campaign and bias trends that ranged from -0.3 to $+2.2 \mathrm{~cm} \mathrm{yr}^{-1}$ over the L2a-L2f period. Given the different surface types, data locations, spatial sampling, and methodologies used in these estimates, it is not surprising that the estimated biases differ. However, since the intercampaign bias trends (or their underlying biases) are supposed to be applied as corrections to all ICESat data, it is important to understand the reasons for and implications of the variability between the different estimates.

We identify three components of the measured intercampaign biases: (1) the contribution of the G-C offset; (2) bias due to all other instrument error sources; and (3) bias estimation errors due to actual elevation/range changes from unmodeled physical processes such as surface change and atmospheric scattering over the selected calibration surfaces.
The contributions of all three components will vary according to the data and methodology used in the bias estimation. For instance, we demonstrated in Sect. 3.4 how the impact of the G-C offset differs by a few $\mathrm{mm} \mathrm{yr}^{-1}$ between two ice shelves on the same continent because of different spatiotemporal data sampling. We might also expect, for example, differences between land-, ocean- and ice-determined biases due to systematic differences in cloud cover or surface geometry (e.g., sea-state effects). Larger differences are likely if biases are being estimated over surfaces that are assumed to be stable but are not, or over surfaces whose time variance is imperfectly known.

Applying the G-C correction removes the first component of the intercampaign biases and thus will alter existing intercampaign bias estimates. Specifically, we can expect the G-C correction to decrease intercampaign bias trends by 0.92 to $1.90 \mathrm{~cm} \mathrm{yr}^{-1}$ depending on the campaigns used (Table 2, Trend C). This means that the G-C offset is a significant contributor to the intercampaign biases, although the large spread of the intercampaign bias estimates suggests that significant residual variability will remain in all estimates after the G-C correction - at the level of individual campaign biases and/or in the overall trends themselves. Validation using the two ICESat tracks that cross the salar de Uyuni DEM (Fig. 1) confirms that the impact on the fitted elevation trend from applying the G-C correction to individual ICESat shots is almost the same as what we predict from the global analysis in Sect. $3.2\left(-0.92 \mathrm{~cm} \mathrm{yr}^{-1}\right.$ predicted vs. $-1.17 \mathrm{~cm} \mathrm{yr}^{-1}$ actual for L2a-L2f). However, the magnitude of the Uyuni intercampaign bias trend (which changed from $0.67 \pm 0.47 \mathrm{~cm} \mathrm{yr}^{-1}$ to $-0.50 \pm 0.36 \mathrm{~cm} \mathrm{yr}^{-1}$ ) did not appreciably drop, which illustrates our point that post-correction errors are likely to remain despite improvements in accuracy and precision.

Of importance to previous studies that used data containing the G-C offset, recent studies have suggested (e.g., Rignot et al., 2013) that applying a set of intercampaign biases implicitly corrects for the impact of the G-C offset, at least at the level of the mean elevation for each campaign. While technically true, we are concerned that this is not a satisfactory way to make the G-C correction. Applying empirical intercampaign biases may partially correct the effect of the G-C offset, but the variability of intercampaign biases from different sources suggests that this approach can introduce additional errors in $\mathrm{d} h / \mathrm{d} t$ estimates. We recommend instead that investigators explicitly correct for the known G-C offset using one of the methods described in Sect. 2.4.

Finally, we consider whether intercampaign biases should be applied after making the G-C correction. Investigators should be aware that:

1. There is still no authorized or consensus set of intercampaign biases.

2. Differences between biases from different sources can be statistically significant. 

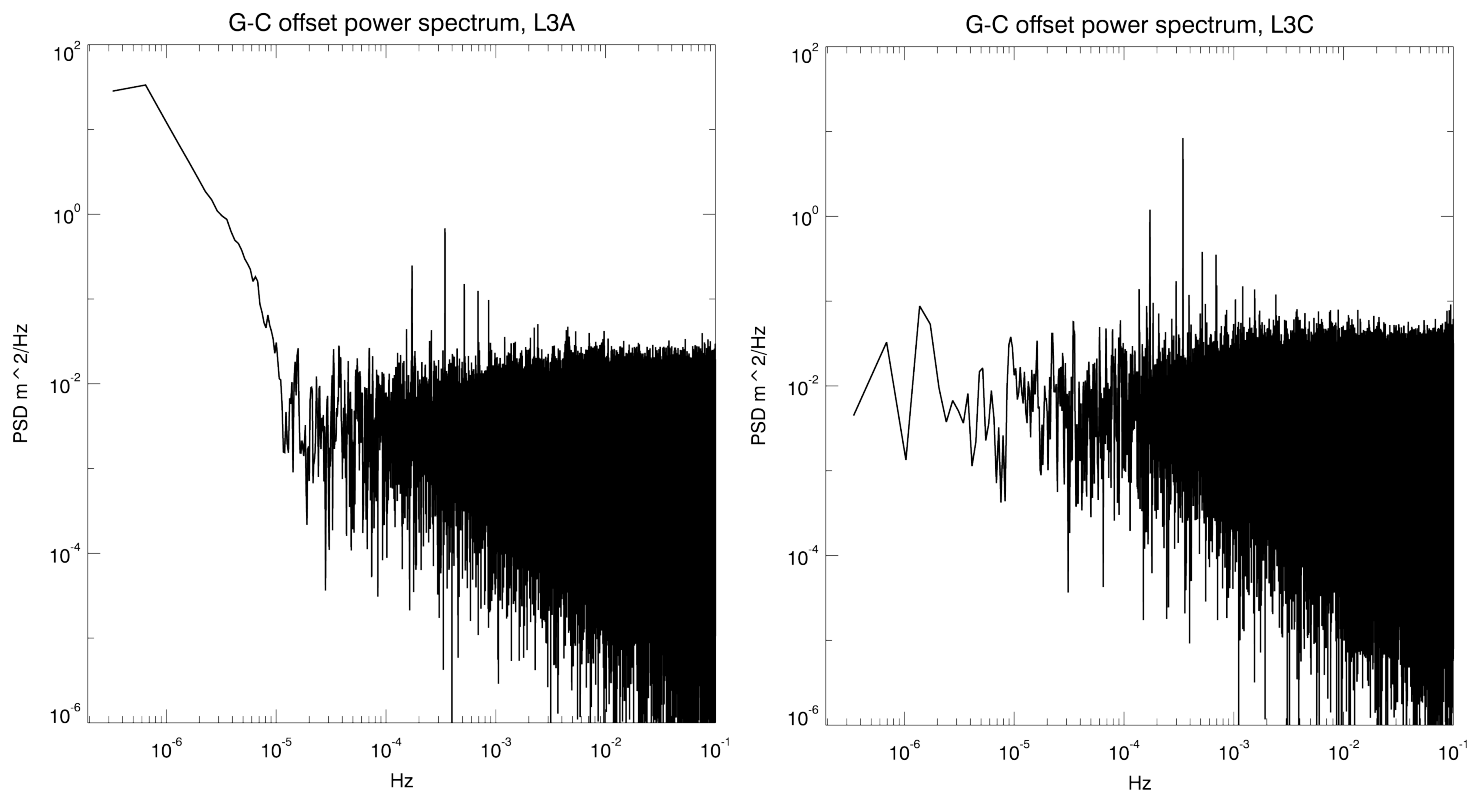

Fig. 6. Power spectrum of G-C offset for campaigns L3a (left) and L3c (right), showing a flat spectrum beyond $10^{-5} \mathrm{~Hz}$, narrow spectral peaks at harmonics of the orbital frequency of ICESat, and different behavior at lower frequencies. The main difference between the two campaigns is that the moving average of the G-C offset jumps abruptly in L3a while it is flat in L3c (see Fig. 4b).

3. Bias estimates must be G-C-corrected before being applied to G-C-corrected elevations.

4. The biases for each campaign should be applied to individual elevations before $\mathrm{d} h / \mathrm{d} t$ is estimated. Those who wish to apply intercampaign bias trends directly to $\mathrm{d} h / \mathrm{d} t$ estimates should be aware that they must correct bias trends for sampling effects and the weights used in the $\mathrm{d} h / \mathrm{d} t$ calculation, as discussed earlier.

\section{Conclusions and outlook}

We have reported on a range correction to the ICESat Level 1 data that removes the effect of an erroneous travel time calculation in the Level 1 data (the G-C offset). The impact of the G-C offset on ice-sheet elevation trends $(\mathrm{d} h / \mathrm{d} t)$ can vary substantially depending on the time span of investigation and the data sampling in each observation campaign. If those factors are carefully considered, we have shown that it is possible to reproduce the effect of the G-C offset to within a few $\mathrm{mm} \mathrm{yr}^{-1}$ at a regional scale. Ideally, users should apply the G-C offset corrections to the data themselves based on the GLA05 data product or use correction files provided by NSIDC (http://nsidc.org/data/icesat/ correction-to-product-surface-elevations.html) until a final release of the ICESat data becomes available.

Additional work is still needed to characterize the elevation errors that will remain after the G-C offset is removed. This work includes the revision and ultimate reconciliation of various estimates of ICESat intercampaign biases, which will change as a result of the G-C offset correction. The large variation in existing estimates of intercampaign biases suggests that the problem of estimating empirical errors is not necessarily any easier than uncovering the root sources of those errors. We also wonder if the formalization of the intercampaign bias as a description for otherwise unmodeled and persistent errors in ICESat elevations may have diverted attention away from the need for a more systematic and methodical effort to identify outstanding error sources in the ICESat data. In particular, we are concerned that a single "universal" set of intercampaign biases (were one to become available) would not be equally relevant across a range of studies using different spatial subsets of data or different data sampling/editing.

The discovery of the G-C offset was the result of having access to an accurately surveyed stable reference surface that allowed us to unambiguously link a component of ICESatmeasured elevation changes to an ICESat timing error. Our approach of correlating elevation misfits with various instrument parameters can and should be applied to a broader sample of reference surfaces to provide a greater range of parameter values, thereby increasing the diagnostic power of the correlation analysis. There are many active and potential reference sites around the globe, and we believe that the satellite altimetry community should attempt to link these into a single virtual surface for altimeter calibration and validation. Future missions might consider increasing both the resources and expectations for these efforts. 


\section{Appendix A}

\section{Linear regression of mean G-C offsets to estimate the G-C impact on ICESat elevation trends}

We take the chi-square merit function for the linear fit to $N$ pairs of time/elevation data to be

$\chi^{2}(a, b)=\sum_{i=0}^{N-1}\left[\frac{\left(h_{i}+\Delta h_{i}\right)-\left(a+b t_{i}\right)}{\sigma_{i}}\right]^{2}$,

where the $t_{i}$ are points in time corresponding to different ICESat campaigns, $h_{i}$ are the true surface elevations, $\Delta h_{i}$ are the corresponding G-C offsets, and $\sigma_{i}$ are the standard deviations assumed for $\left(h_{i}+\Delta h_{i}\right)$. The maximum likelihood estimate of the slope (or trend) $b$ of the linear fit is the closedform solution obtained from minimizing A1 (Press et al., 2007)

$b=\frac{\left[\sum_{i} \frac{1}{\sigma_{i}^{2}}\right]\left[\sum_{i} \frac{\left(h_{i}+\Delta h_{i}\right) t_{i}}{\sigma_{i}^{2}}\right]-\left[\sum_{i} \frac{t_{i}}{\sigma_{i}^{2}}\right]\left[\sum_{i} \frac{h_{i}+\Delta h_{i}}{\sigma_{i}^{2}}\right]}{\left[\sum_{i} \frac{1}{\sigma_{i}^{2}}\right]\left[\sum_{i} \frac{t_{i}^{2}}{\sigma_{i}^{2}}\right]-\left[\sum_{i} \frac{t_{i}}{\sigma_{i}^{2}}\right]^{2}}$.

Since A2 is linear in $h+\Delta h_{i}$, it can be rewritten as the sum of separate solutions for $h$ and $\Delta h_{i}$

$$
\begin{array}{r}
b=\frac{\left[\sum_{i} \frac{1}{\sigma_{i}^{2}}\right]\left[\sum_{i} \frac{h_{i} t_{i}}{\sigma_{i}^{2}}\right]-\left[\sum_{i} \frac{t_{i}}{\sigma_{i}^{2}}\right]\left[\sum_{i} \frac{h_{i}}{\sigma_{i}^{2}}\right]}{\left[\sum_{i} \frac{1}{\sigma_{i}^{2}}\right]\left[\sum_{i} \frac{t_{i}^{2}}{\sigma_{i}^{2}}\right]-\left[\sum_{i} \frac{t_{i}}{\sigma_{i}^{2}}\right]^{2}} \\
+\frac{\left[\sum_{i} \frac{1}{\sigma_{i}^{2}}\right]\left[\sum_{i} \frac{\Delta h_{i} t_{i}}{\sigma_{i}^{2}}\right]-\left[\sum_{i} \frac{t_{i}}{\sigma_{i}^{2}}\right]\left[\sum_{i} \frac{\Delta h_{i}}{\sigma_{i}^{2}}\right]}{\left[\sum_{i} \frac{1}{\sigma_{i}^{2}}\right]\left[\sum_{i} \frac{t_{i}^{2}}{\sigma_{i}^{2}}\right]-\left[\sum_{i} \frac{t_{i}}{\sigma_{i}^{2}}\right]^{2}}
\end{array}
$$

or

$b=b_{\text {surface }}+b_{\mathrm{G}-\mathrm{C}}$.

The contribution of the G-C offset to the trend in the data can therefore be considered separately from the contribution of the surface elevations themselves, although the weighting will be the same in both cases.

To scale these conclusions from a single evaluation cell to an entire study area, we note that the ice volume change for a given region is calculated by summing the contribution of many independent trend estimates

$$
\begin{aligned}
\frac{\mathrm{d} V}{\mathrm{~d} t} & =\sum_{j} b_{j} A_{j}=\sum_{j}\left[b_{\text {surface }_{j}}+b_{\mathrm{G}-\mathrm{C}_{j}}\right] A_{j} \\
& =\sum_{j}\left[b_{\text {surface }_{j}} A_{j}+b_{\mathrm{G}-\mathrm{C}_{j}} A_{j}\right]
\end{aligned}
$$

with separate terms for the true surface volume change and volume change from the $\mathrm{G}-\mathrm{C}$ offset. If we make the simplifying assumption that the area $A_{j}$ of each evaluation cell is the same (most studies interpolate volume/mass estimates to the nodes of a regular grid) and take $M$ to be the number of cells, the $\mathrm{G}-\mathrm{C}$ volume change term from Eq. (A5) can be written

$$
\frac{\mathrm{d} V_{\mathrm{G}-\mathrm{C}}}{\mathrm{d} t}=A \sum_{j=0}^{M-1} b_{\mathrm{G}-\mathrm{C}_{j}}=M A \sum_{j=0}^{M-1} \frac{b_{\mathrm{G}-\mathrm{C}_{j}}}{M} .
$$

Substituting into Eq. (A6) the linear regression solution for $b_{\mathrm{G}-\mathrm{C}}$ from Eq. (A3), taking the values for $t_{i}$ and $\sigma_{i}$ to be the same everywhere for a given campaign (although different between campaigns), and distributing the summation over $j$ gives

$$
\begin{aligned}
& \frac{\mathrm{d} V_{\mathrm{G}-\mathrm{C}}}{\mathrm{d} t}= \\
& M A \frac{\left[\sum_{i} \frac{1}{\sigma_{i}^{2}}\right]\left[\sum_{i} \frac{t_{i}}{\sigma_{i}^{2}} \Delta \bar{h}_{i}\right]-\left[\sum_{i} \frac{t_{i}}{\sigma_{i}^{2}}\right]\left[\sum_{i} \frac{1}{\sigma_{i}^{2}} \Delta \bar{h}_{i}\right]}{\left[\sum_{i} \frac{1}{\sigma_{i}^{2}}\right]\left[\sum_{i} \frac{t_{i}^{2}}{\sigma_{i}^{2}}\right]-\left[\sum_{i} \frac{t_{i}}{\sigma_{i}^{2}}\right]^{2}}
\end{aligned}
$$

where

$$
\Delta \bar{h}_{i}=\sum_{j=0}^{M-1} \frac{\Delta h_{i j}}{M}
$$

is the mean G-C offset value for the campaign indexed by $i$, and

$$
\frac{\left[\sum_{i} \frac{1}{\sigma_{i}^{2}}\right]\left[\sum_{i} \frac{t_{i}}{\sigma_{i}^{2}} \Delta \bar{h}_{i}\right]-\left[\sum_{i} \frac{t_{i}}{\sigma_{i}^{2}}\right]\left[\sum_{i} \frac{1}{\sigma_{i}^{2}} \Delta \bar{h}_{i}\right]}{\left[\sum_{i} \frac{1}{\sigma_{i}^{2}}\right]\left[\sum_{i} \frac{t_{i}^{2}}{\sigma_{i}^{2}}\right]-\left[\sum_{i} \frac{t_{i}}{\sigma_{i}^{2}}\right]^{2}}
$$

is the maximum likelihood estimate of the G-C offset trend from the mean G-C offsets $\Delta \bar{h}_{i}$.

Estimates of $\Delta \bar{h}_{i}$ are given in Table 1 (mean G-C offset by campaign), which our analysis in Sect. 3.3 suggests should be valid anywhere on Earth. Equation (A9) is evaluated by estimating the linear trend $\Delta \bar{h}_{i}$ ordered in time (using whatever $\sigma_{i}$ were chosen for the surface change analysis) and the result is used in A7 to estimate the impact of the G-C offset on ICESat elevation change trends assuming identical sampling of the various ICESat campaigns.

Finally, we consider the impact of sampling, whereby the number of valid ICESat returns can be different for different campaigns. In Eq. (A3), this is manifested by having some campaigns with a large number of elevations/offsets and some with few (or even no) elevations/offsets, which implicitly down-weights campaigns with fewer samples. We would like to have a way of representing sampling when we fit linear trends to the G-C offset means in Eq. (A9). While 
it is beyond the scope of this paper to offer a proof, bootstrap analysis will confirm that a weighting that accounts for non-uniform sampling is

$\sigma_{i}^{2}=\frac{\sigma_{i}^{2}}{S_{i}} \frac{\sum S_{i}}{N}$

where the $S_{i}$ are the number of samples for a given campaign in the study area and $N$ is the total number of campaigns (as in Eq. A1). This formulation roughly preserves the value of the formal error on the slope estimate obtained from uniformvariance weighting. In the uniform-variance scenario typical for ICESat, what matters for the trend estimate is the relative number of samples between campaigns, not the absolute numbers.

Acknowledgements. The authors would like to acknowledge the valuable critique and feedback provided by J. Zwally and his group at NASA's Goddard Space Flight Center on an earlier version of this manuscript. We would also like to thank M. Siegfried of the Scripps Institution of Oceanography for an early internal review of the manuscript, and B. Csatho and an anonymous reviewer for their helpful review comments. This work was supported by NASA's Research Opportunities in Space and Earth Sciences program under grant number NNX12AG67G.

Edited by: I. M. Howat

\section{References}

Abdalati, W., Zwally, H. J., Bindschadler, R., Csatho, B., Farrell, S., Fricker, H., Harding, D., Kwok, R., Lefsky, M., Markus, T., Marshak, A., Neumann, T., Palm, S., Schutz, B., Smith, B., Spinhirne, J., and Webb, C.: The ICESat-2 laser altimetry mission, Proceedings of the IEEE, 98, 735-751, doi:10.1109/JPROC.2009.2034765, 2010.

Abshire, J. B., Sun, X., Riris, H., Sirota, M., McGarry, J., Palm, S., Ketchum, E. A., and Follas, R. B.: Geoscience Laser Altimeter System (GLAS) on the ICESat Mission: Pre-launch and onorbit measurement performance, Geoscience and Remote Sensing Symposium, 2003, Proceedings, 21-25, July 2003.

Borsa, A. A., Minster, J. B., Bills, B. G., and Fricker, H. A.: Modeling long-period noise in kinematic GPS applications, J. Geodesy, 81, 157-170, doi:10.1007/s00190-006-0097-x, 2007.

Borsa, A. A., Fricker, H. A., Bills, B. G., Minster, J. B., Carabajal, C. C., and Quinn, K. J.: Topography of the salar de Uyuni, Bolivia from kinematic GPS, Geophys. J. Int., 172, 31-40, doi:10.1111/j.1365-246X.2007.03604.x, 2008.

Brenner, A. C., Zwally, H. J., Bentley, C. R., Csathó, B. M., Harding, D. J., Hofton, M. A., Minster, J.-B., Roberts, L. A. Saba, J. L., Thomas, R. H., and Yi, D.: Derivation of range and range distributions from laser pulse waveform analysis for surface elevations, roughness, slope, and vegetation heights, Algorithm Theoretical Basis Document, version 4.1 (available at: http://www.csr.utexas.edu/glas/atbd.html), Cent. for Space Res., Univ. of Tex., Austin, 2003.

Brenner, A. C., DiMarzio, J., and Zwally, H. J.: Precision and Accuracy of Satellite Radar and Laser Altimeter Data Over the
Continental Ice Sheets, IEEE T. Geosci. Remote, 45, 321-331, doi:10.1109/TGRS.2006.887172, 2007.

Brunt, K. M., Borsa, A. A., and Fricker, H. A.: Repeated GPS surveys of the salar de Uyuni for continued calibration of ICESat altimeter data, Fall Meeting, AGU, San Francisco, CA, 14-18 December, 2009.

Ewert, H., Popov, S. V., Richter, A., Schwabe, J., Scheinert, M., and Dietrich, R.: Precise analysis of ICESat altimetry data and assessment of the hydrostatic equilibrium for subglacial Lake Vostok, East Antarctica, Geophys. J. Int., 191, 557-568, 2012.

Fricker, H. A., Borsa, A., Minster, B., Carabajal, C., Quinn, K., and Bill, B.: Assessment of ICESat performance at the salar de Uyuni, Bolivia, Geophys. Res. Lett., 32, L21S06, doi:10.1029/2005GL023423, 2005.

Fricker, H. A. and Padman, L.: Ice shelf grounding zone structure from ICESat laser altimetry, Geophys. Res. Lett., 33, L15502, doi:10.1029/2006GL026907, 2006.

Gardner, A. S., Moholdt, G., Cogley, J. G., Wouters, B., Arendt, A. A., Wahr, J., Berthier, E., Hock, R., Pfeffer, W. T., Kaser, G., Ligtenberg, S. R. M., Bolch, T., Sharp, M. J., Hagen, J. O., van den Broeke, M. R., and Paul, F.: A Reconciled Estimate of Glacier Contributions to Sea Level Rise: 2003 to 2009, Science, 340, 852-857, doi:10.1029/2011GL046583, 2013.

Gunter, B., Urban, T., Riva, R., Helsen, M., Harpold, R., Poole, S., Nagel, P., Schutz, B., and Tapley, B.: A comparison of coincident GRACE and ICESat data over Antarctica, J. Geodesy, 83, 10511060, doi:10.1007/s00190-009-0323-4, 2009.

Gunter, B. C., Didova, O., Riva, R. E. M., Ligtenberg, S. R. M., Lenaerts, J. T. M., King, M. A., van den Broeke, M. R., and Urban, T.: Empirical estimation of present-day Antarctic glacial isostatic adjustment and ice mass change, The Cryosphere Discuss., 7, 3497-3541, doi:10.5194/tcd-7-3497-2013, 2013.

Hofton, M. A., Luthcke, S. B., and Blair, J. B.: Estimation of ICESat intercampaign elevation biases from comparison of lidar data in East Antarctica, Geophys. Res. Lett., 40, 5689-5703, doi:10.1002/2013GL057652, 2013.

Hurkmans, R. T. W. L., Bamber, J. L., and Griggs, J. A.: Brief communication "Importance of slope-induced error correction in volume change estimates from radar altimetry", The Cryosphere, 6, 447-451, doi:10.5194/tc-6-447-2012, 2012.

Koenig, L., Martin, S., Studinger, M., and Sonntag, J.: Polar Airborne Observations Fill Gap in Satellite Data, EOS Trans. AGU, 91, 38, 2010.

Kwok, R., Cunningham, G. F., Manizase, S. S., and Krabill, W. B.: Arctic sea ice freeboard from IceBridge acquisitions in 2009: Estimates and comparisons with ICESat, J. Geophys. Res., 117, C02018, doi:10.1029/2011JC007654, 2012.

Luthcke, S. B., Rowlands, D. D., Williams, T. A., and Sirota, M.: Reduction of ICESat systematic geolocation errors and the impact on ice sheet elevation change detection, Geophys. Res. Lett., 32, L21S05, doi:10.1029/2005GL023689, 2005.

Magruder, L. A., Webb, C. E., Urban, T. J., Silverberg, E. C., and Schutz, B. E.: ICESat altimetry data product verification at white sands space harbor, IEEE T. Geosci. Remote, 45, 147-155, doi:10.1109/TGRS.2006.885070, 2007.

Magruder, L. A., Ricklefs, R. L., Silverberg, E. C., Horstman, M. F., Suleman, M. A., and Schutz, B. E.: ICESat geolocation validation using airborne photography, IEEE T. Geosci. Remote, 48, 2758-2766, doi:10.1109/TGRS.2010.2040831, 2010. 
Padman, L., Fricker, H. A., Coleman R., Howard S. L., and Erofeeva, S.: A new tide model for the Antarctic ice shelves and seas, Ann. Glaciol., 34, 247-254, 2002.

Press, W. H., Teukolsky, S. A., Vetterling, W. T., and Flannery, B. P.: Numerical Recipes: The Art of Scientific Computing, 3rd Edn., Cambridge University Press, New York, 2007.

Pritchard, H. D., Arthern, R. J., Vaughan, D. G., and Edwards, L. A.: Extensive dynamic thinning on the margins of the Greenland and Antarctic ice sheets, Nature, 461, 971-975, doi:10.1038/nature08471, 2009.

Pritchard, H. D., Ligtenberg, S. R. M., Fricker, H. A., Vaughan, D. G., Van den Broeke, M. R., and Padman, L.: Antarctic ice-sheet loss driven by basal melting of ice shelves, Nature, 484, 502-505, doi:10.1038/nature10968, 2012.

Rignot, E., Jacobs, S., Mouginot, J. and Scheuchl, B.: Ice shelf melting around Antarctic, Science, 341, 266-270, doi:10.1126/science.1235798, 2013.

Riva, R. E. M., Gunter, B. C., Urban, T. J., Vermeersen, B. L. A., Lindenbergh, R. C., Helsen, M. M., Bamber, J. L., van de Wal, R. S. W., van den Broeke, M. R., and Schutz, B. E.: Glacial isostatic adjustment over Antarctica from combined ICESat and GRACE satellite data, Earth Planet. Sc. Lett., 288, 516-523, doi:10.1016/j.epsl.2009.10.013, 2009.

Schenk, T. and Csathó, B.: A New Methodology for Detecting Ice Sheet Surface Elevation Changes From Laser Altimetry Data, Geoscience and Remote Sensing, IEEE T. Geosci. Remote, 50, 3302-3316, doi:10.1109/TGRS.2011.2182357, 2012.

Schutz, B. E., Zwally, H. J., Shuman, C. A., Hancock, D., and DiMarzio, J. P.: Overview of the ICESat Mission, Geophys. Res. Lett., 32, L21S01, doi:10.1029/2005GL024009, 2005.

Shepherd, A., Ivins, E. R., Geruo, A., Barletta, V. R., Bentley, M. J., Bettadpur, S., Briggs, K. H., Bromwich, D. H., Forsberg, R., Galin, N., Horwath, M., Jacobs, S., Joughin, I., King, M. A., Lenaerts, J. T. M., Li, J., Ligtenberg, S. R. M., Luckman, A., Luthcke, S. B., McMillan, M., Meister, R., Milne, G., Mouginot, J., Muir, A., Nicolas, J. P., Paden, J., Payne, A. J., Pritchard, H., Rignot, E., Rott, H., Sørensen, L. S., Scambos, T. A., Scheuchl, B., Schrama, E. J. O., Smith, B., Sundal, A. V., van Angelen, J. H., van de Berg, W. J., van den Broeke, M. R., Vaughan, D. G., Velicogna, I., Wahr, J., Whitehouse, P. L., Wingham, D. J., Yi, D., Young, D., and Zwally, H. J.: A reconciled estimate of ice-sheet mass balance, Science, 338, 6111, 1183-1189, doi:10.1126/science.1228102, 2012.
Siegfried, M. R., Hawley, R. L., and Burkhart, J. F.: High-resolution ground-based GPS measurements show intercampaign bias in ICESat elevation data near Summit, Greenland, IEEE T. Geosci. Remote, 49, 3393-3400, doi:10.1109/TGRS.2011.2127483, 2011.

Shuman, C. A., Zwally, H. J., Schutz, B. E., Brenner, A. C., DiMarzio, J. P., Suchdeo, V. P., and Fricker, H. A.: ICESat Antarctic elevation data: preliminary precision and accuracy assessment, Geophys. Res. Lett., 33, L07501, doi:10.1029/2005GL025227, 2006.

Shuman, C. A., Harding, D. J., Dimarzio, J. P., Sun, X., Suchdeo, V. P., and Brenner, A.: Empirical correction of residual error in the ICESat-1 altimetry time series at Lake Vostok, Fall Meeting, AGU, San Francisco, CA, 14-18 December, 2009.

Smith, B. E., Fricker, H. A., Joughin, I. R., and Tulaczyk, S.: An inventory of active subglacial lakes in Antarctica detected by ICESat (2003-2008), J. Glaciol., 55, 573-595, doi:10.3189/002214311795306682, 2009.

Urban, T. J. and Schutz, B. E.: ICESat sea level comparisons, Geophys. Res. Lett., 32, L23S10, doi:10.1029/2005GL024306, 2005.

Urban, T., Borsa, A., Brunt, K., Felikson, D., Fricker, H., Hawley, B., Hofton, M., Luthcke, S., Pie, N., Schutz, B., Shuman, C., Yi, D., and Zwally, J.: Summary of ICESat-1 inter-campaign elevation biases and detection methods, Fall Meeting, AGU, San Francisco, CA, 3-7 December, 2012.

Zwally, H. J., Schutz, B. E., Abdalati, W., Abshire, J. B., Bentley, C. R., Brenner, A. C., Bufton, J. L., Dezio, J.,Hancock, D., Harding, D. J., Herring, T. A., Minster, J. B., Quinn, K., Palm, S., Spinhirne, J. D., and Thomas, R. H.: ICESat's laser measurements of polar ice, atmosphere, ocean and land, J. Geodyn., 34, 405-445, doi:10.1016/S0264-3707(02)00042-X, 2002.

Zwally, H. J., Li, J., Brenner, A. C., Beckley, M., Cornejo, H. G., DiMarzio, J., Giovinetto, M. B., Neumann, T. A., Robbins, J., Saba, J. L., Yi, D., and Wang, W.: Greenland ice sheet mass balance: distribution of increased mass loss with climate warming; 2003-07 vs. 1992-02, J. Glaciol., 57, 88-102, doi:10.3189/002214311795306682, 2011. 